\title{
Publisher Correction: Causes of model dry and warm bias over central U.S. and impact on climate projections
}

\author{
Yanluan Lin (1) 1, Wenhao Dong (10 1, Minghua Zhang ${ }^{2,3}$, Yuanyu Xie ${ }^{1}$, Wei Xue ${ }^{1,4}$, Jianbin Huang ${ }^{1}$ \& Yong Luo ${ }^{1}$
}

Nature Communications 8:881 https://doi.org/10.1038/s41467-017-01040-2; Article published online: 12 Oct 2017

The original version of this Article contained an error in Figure 2. In panel a, the $x$ axis of the graph was incorrectly labeled 'precipitation bias', and should have read 'negative precipitation bias'. This error has been corrected in both the PDF and HTML versions of the Article.

Published online: 11 January 2018

\begin{abstract}
(c) (i) Open Access This article is licensed under a Creative Commons Attribution 4.0 International License, which permits use, sharing, adaptation, distribution and reproduction in any medium or format, as long as you give appropriate credit to the original author(s) and the source, provide a link to the Creative Commons license, and indicate if changes were made. The images or other third party material in this article are included in the article's Creative Commons license, unless indicated otherwise in a credit line to the material. If material is not included in the article's Creative Commons license and your intended use is not permitted by statutory regulation or exceeds the permitted use, you will need to obtain permission directly from the copyright holder. To view a copy of this license, visit http://creativecommons.org/licenses/by/4.0/.
\end{abstract}

(C) The Author(s) 2018

\footnotetext{
${ }^{1}$ Ministry of Education Key Laboratory for Earth System Modeling, Department of Earth System Science, and Joint Center for Global Change Studies (JCGCS), Tsinghua University, Beijing 100084, China. ${ }^{2}$ School of Marine and Atmospheric Sciences, Stony Brook University, Stony Brook, NY $11794-5000$, USA. ${ }^{3}$ Institute of Atmospheric Physics, Chinese Academy of Sciences, Beijing 100029, China. ${ }^{4}$ Department of Computer Science and Technology, Tsinghua University, Beijing 100084, China. Yanluan Lin and Wenhao Dong contributed equally to this work. Correspondence and requests for materials should be addressed to Y.L. (email: yanluan@tsinghua.edu.cn) or to M.Z. (email: minghua.zhang@stonybrrok.edu)
} 